\title{
İnsan-Robot Etkileşiminde İnsan Güvenliği için Çok Kanallı İletişim Kullanarak Evrişimli Sinir Ă̆ı Tabanlı Bir Yazılımının Geliştirilmesi ve Uygulaması
}

\author{
Mustafa Can BINGOL ${ }^{1 *}$, Ömür AYDOĞMUŞ ${ }^{2}$ \\ ${ }^{1 *}$ Fırat Üniversitesi Teknoloji Fakültesi Mekatronik Mühendisliği, ELAZIĞ \\ ${ }^{2}$ Fırat Üniversitesi Teknoloji Fakültesi Mekatronik Mühendisliği, ELAZIĞ \\ 1*mustafacanbingol@gmail.com, ${ }^{2}$ oaydogmus@gmail.com
}

(Geliș/Received: 24/04/2019;

Kabul/Accepted: 02/07/2019)

\begin{abstract}
Öz: Teknolojinin hızlı bir şekilde artması ile birlikte robotlara olan ilgi de giderek artmaktadır. Üretim amaçlı birçok uygulamada robotlar tek başına veya insanlar ile birlikte çalışmaları gerekmektedir. Robotik alanda bilgi ve tecrübeye sahip olmayan birçok işletme bu teknolojinin gerisinde kalmaktadır. İnsan-robot etkileşimi (İRE), robotik alanda uzman olmayan kişilerin robotları kolay bir şekilde kontrol etmesini sağlayarak robotların kullanımı yaygınlaştıracaktır. Bu robotlar istenilen görevleri yerine getirmelerinin yanı sıra aynı zamanda çalıştığı ortamda bulunan insanların güvenliğini de sağlamak zorundadırlar. Bundan dolayı, bu çalışmada insan güvenliği göz önüne alınarak güvenli insan-robot etkileşimi yazılımı (GİREY) geliştirilmiştir ve robot ile aynı ortamda çalışan insanın güvenliği sağlanmıştır. GİREY çok kanallı iletişimi kullanarak, çalıșma ortamından görsel ve işitsel bilgileri toplar. GİREY topladığı bu bilgiler doğrultusunda evrișimli sinir ağı kullanarak ortamın tehlike düzeyini belirler ve robotun çalışma hızını kontrol eder. Geliştirilen GİREY bir endüstriyel robot olan KUKA KR Agilus KR6 R900 sixx üzerinde test edilmiştir ve başarılı sonuçlar elde edilmiştir.
\end{abstract}

Anahtar kelimeler: çok kanallı iletişim, evrişimli sinir ağı, insan-robot etkileşimi, endüstriyel robotlar.

\section{Development and Implementation of a Convolutional Neural Network Based Software Using Multichannel Communication for Human Security in Human-Robot Interaction}

\begin{abstract}
The interest in robots is also increasing with the rapid increase in technology. In many manufacturing applications, robots must work alone or they must work with human. Many businesses do not have knowledge and experience in the robotics, so they are lagging behind the technology. Human-robot interaction (HRI) will enable that non-expert human easily controls robots and, therefore, the use of the robot will become widespread. These robots, which are widespread, must not only execute the desired task but also provide human safety existed in the working environment. Hence, safe human-robot interaction software (SHRIS) was developed in this study and the safety of the human working in the same environment as the robot was undertaken control. SHRIS collects visual and audio information from the working environment using multimodal communication. According to this information, SHRIS determines the danger level of the environment by using convolutional neural network and controls the speed of the robot. Developed SHRIS was tested on KUKA KR Agilus KR6 R900 sixx, which is industrial robots, and successful results were obtained.
\end{abstract}

Key words: Multimodal communication, convolutional neural network, human-robot interaction, industrial robots.

\section{Giriş}

İnsan-robot etkileşimdeki son gelişmeler sayesinde, robotlar gelecekte birçok alanda insanların günlük yaşantılarının bir parçası olacaklardır. Örneğin Fong vd. yapmış olduğu çalışmada robot kol yürüme terapisi için kullanılırken [1], bir diğer Lafleche ve ekibinin yapmış olduğu çalışmada Baxter robotu insan gibi sosyal bir çevrede görmeye dayalı öğrenme işlemini gerçekleştirmiştir [2]. Bu çalışmaların yanı sıra Yatsuda ve ekibinin yapmış olduğu çalışma İRE'nin günlük hayatta sıkça karşılaşmaya başlayacağımızın kanıtı niteliğindedir [3]. Yatsuda ve ekibinin yapmış olduğu bu çalışmada yaşlı ve yalnız insanlar için bir robot tasarlanarak, bu insanların bakımı sağlanmıştır. Endüstriyel bir çalışma olan Du ve ekibinin gerçekleştirmiş olduğu çalışmada, endüstriyel bir robot konuşma ve el hareketleri yardımı ile programlanmıştır [4].

İRE insanların günlük yaşantısını kolaylaştıırken aynı zamanda insan güvenliğini tehlikeye sokmaktadır. Çünkü robotlar bir noktadan bir noktaya yönlendirilirken ölümcül kazalara yol açabilirler. Bundan dolayı, yaklaşı son yirmi yıldır farklı algılayıcı ve bilgi işleme yöntemleri kullanılarak güvenlik problemleri çözülmeye çalışılmaktadırlar. Zurada vd. 2001 yılında yapmış olduğu çalışmada, bir algılayıcı grubundan alınan bilgileri birleştirerek Yapay Sinir Ağına (YSA) uygulanmış ve YSA'nın çıkışına bırakılan bulanık sınıflandırıcı ile robotun

\footnotetext{
* Sorumlu yazar: mustafacanbingol@ gmail.com. Yazarların ORCID Numarası: ${ }^{1}$ 0000-0001-5448-8281, ${ }^{2}$ 0000-0001-8142-1146
} 
çalıştığı ortamın insan için tehlike düzeyini belirlemiştir [5]. Bir diğer çalışmada, işçi yeleği üzerinde kare şeklinde yerleştirilmiş 16 adet kapsitif algılayıcı ile bu algılayıcılardan gelen veriler Destek Vektör Makinası (DVM) yardımı ile sınıflandırılarak bir güvenlik yazılımı oluşturulmuştur. Oluşturulan bu güvenlik yazılımı sayesinde endüstriyel bir robot ile insanın birlikte güvenli çalışması sağlanmıştır [6]. Lee ve ekibi ise iki adet lazer metreden alınan bilgileri Gizli Markov Modeli (GMM) kullanarak robot operatörü için tehlike analizi yapmışlardır [7]. Başka bir çalışmada, robotun çalıştığı ortama serilen bir algılayıcı yüzeyi sayesinde, insanların bastığı yerleri bir YSA yardımı ile algılayıp bu bilgiye göre robotun insana çarpmasını engelleyerek İRE ortamı güvenli hale getirilmiştir [8]. Sisbot ve Alami yaptıkları çalışmada, robot hareketlerini insanlar için sadece güvenli değil aynı zamanda konforlu hale getirmişlerdir [9] ve kızılötesi sensörlerin kullanıldığı diğer bir çalışmada, robot üzerine yerleştirilmiş algılayıcılardan alınan bilgilere göre robot insan çarpışması engellenmiştir [10]. Diğer bir çalışmada uyumlu uzuv algılayıcısı adı verilen ışık saçan ve ışığı algılayan bir yapı oluşturulmuştur. Oluşturulan bu algılayıcı yapısı robota giyindirilerek insan algılaması sayesinde olası bir insan-robot çarpışmasının önüne geçilmiştir [11]. Diğer bir çalışmada, endüstriyel robotların çalışma ortamına ayrık şekilde çok sayıda radyo frekansı iletişim devresi yerleştirilmiştir. Çalışma uzayına giren bir insanın radyo dalgası gücünü azaltmasından yararlanılarak, robotların çalışma ortamlarında insan varlığını fark etmesi sağlanmıştır [12]. Kimmel ve Hirche'nin yapmış olduğu çalışmada ise değişmezlik kontrolü (Invariance Control) adını verdikleri özel bir kontrol yapısı ile güvenli İRE gerçekleştirmişler [13]. Dean-Leon vd. 2018 yılında yapmış olduğu çalışmada, üç boyutlu ivme, basınç algılayıcısı, yaklaşım algılayıcısı ve iki adet sıcaklık algılayıcısının da bulunduğu çok kanallı bir robot derisi tasarlamışlardır. Yapılan robot derisi sayesinde robotu programlayabilmişler ve güvenli İRE'ni gerçekleştirmişler [14].

İnsanlar iletişim kurarken sadece görerek veya dokunarak değil aynı zamanda bu iletişim yöntemlerinin bir kaçını birlikte kullanırlar. Bu çalışmada, güvenli insan-robot etkileşimi yazılımı insanların görme ve işitme özelliğinden ilham alınarak çok kanallı iletişim çerçevesi kullanarak geliştirilmiştir. Görme yetisi için İntel RealSense D415 derinlik kamerası ve işitme yetisi için Platoon PL-2454 mikrofonu kullanılmıştır. Bu sensörlerden elde edilen görüntü ve ses verileri Evrişimli Sinir Ağları (ESA) yardımı ile anlamlandırılarak endüstriyel bir robot olan KUKA KR Agilus KR6 R900 sixx robotunun kontrolünü sağlamıştır. Bu sayede, endüstriyel bir uygulamada bulunan bir robotun güvenli bir şekilde insan ortamında çalışabilir hale getirilmesi sağlanmıştır. Bu çalışmanın daha önceki yapılan çalışmalardan ayıran özelliklerinden biri; gelişmiş bilgi işleme tekniklerinden olan ESA kullanmasıdır. Diğer bir fark ise; robot ile kullanıcıya herhangi bir giyilebilir algılayıcının olmaması ve özel bir aparata ihtiyaç duymamasıdır. Böylece, kullanıcının nitelikli bir personel olmasına gerek kalmadan endüstriyel bir robot ile sesli ve görsel olarak etkileşime girmesi sağlanmıştır. Ayrıca robot yanında bulunan insanın güvenliği de garanti altına alınmıştır. Geliştirilen yazılım deneysel olarak test edilmiş ve tatminkâr sonuçlar elde edilmiştir.

Çalışmanın bundan sonrası toplam dört bölüm olarak organize edilmiştir. İkinci kısımda güvenli insan-robot etkileşimi yazılımının yapısından bahsedilmiştir. Deney ortamı üçüncü kısımda verilmiştir. Sonuçlar ve değerlendirme sırası ile makalenin dördüncü ve beşinci bölümlerinde verilmiştir.

\section{Güvenli İnsan-Robot Etkileşimi Yazılımı}

GİREY yapıs1; görme, işitme ve robot kontrolü olmak üzere üç temel kısım içermektedir. Bu kısımlar ve bloklar arası kullanılan veriler Şekil 1'de gösterilmiştir.

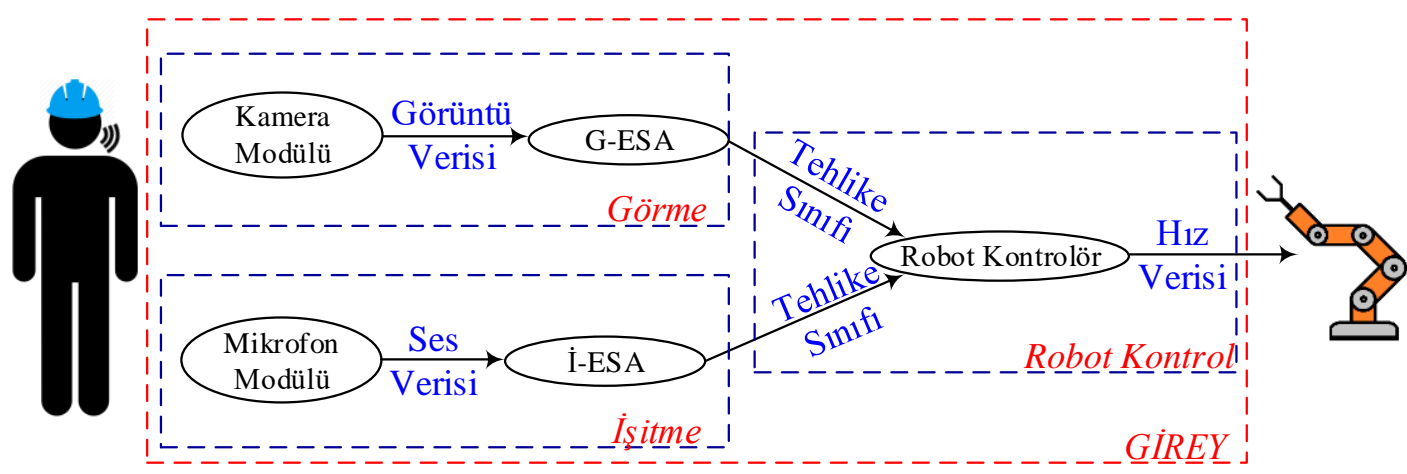

Şekil 1. GİREY'in çalışma prensibi diyagramı 
GİREY'e bağlı bir kamera ve mikrofon yardımı ile ortamdan alınan görüntü ve ses verileri ESA yardımı ile tehlike düzeyi belirlenerek robot kontrol kısmına iletilir. Şekil 1'de bulunan Görsel ESA (G-ESA) görme temelli evrişimli sinir ağını ve İşitsel ESA (İ-ESA) işitme temelli evrişimli sinir ağını temsil etmektedir. Robot kontrol kısmı ise yapılan işlemin hızını robotun çalıştı̆̆ ortamda insan bulunup bulunmama veya bulunan insanın ne kadar uzakta olduğuna göre gerçekleştirmesini sağlar. G-ESA ve İ-ESA kısmı ayrıntılı olarak Şekil 2'de gösterilmiştir.

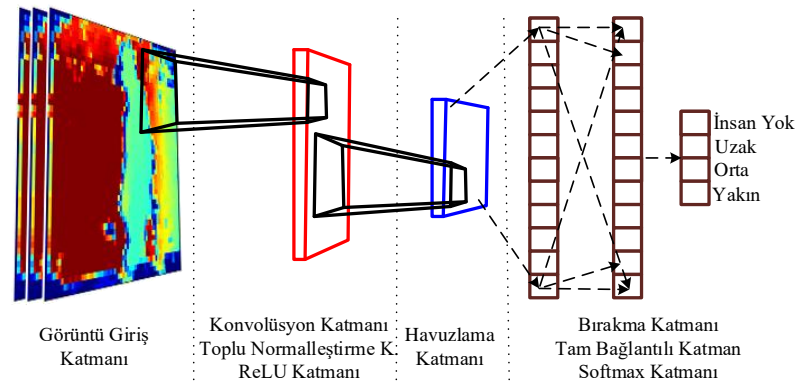

(a)

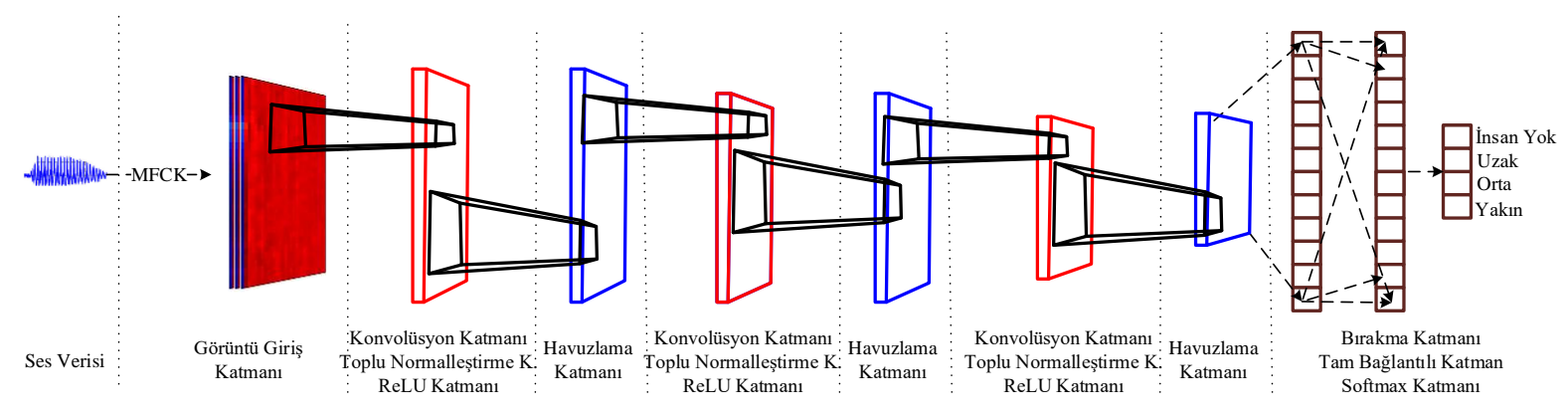

(b)

Şekil 2. (a) G-ESA'nın içyapısı, (b) İ-ESA'nın içyapısı

Şekil 2'de bulunan MFCK Mel Frekansı Cepstral Katsayılarını ifade etmektedir. MFCK özelik çıkartma yöntemi hakkında ayrıntılı bilgiye [15] numaralı yayınından ulaşılabilir. Bu çalışmada, ses sinyalinin her bir parçasından çıkartılan özellik katsayıları alt alta yerleştirilerek bir özellik matrisi elde edilmiştir. Elde edilen bu özellik matrisini sanki gri tonlamalı bir görüntü gibi kabul edilerek ESA'nın giriş katmanına uygulanmıştır. Şekil 2'nin (b) kısmında bulunan özellik matrisi daha rahat anlaşılabilmesi için renklendirilmiştir. G-ESA ve İ-ESA da kullanılan katmanlar sırası ile aşağıda verilmiştir.

- Konvolüsyon Katmanı: ESA yapısında bulunan en yoğun matematiksel işlemin gerçekleştiği katmandır. Katmanın işlevi belirlenen bir maske ile giriş matrisini konvolüsyon işlemine tabi tutmaktır. G-ESA'da konvolüsyon katmanının maske boyutu $5 \times 5$ ve filtre sayısı 128 olarak seçilmiştir. İ-ESA'da konvolüsyon katmanının maske boyutu giriş katmanından çıkışa doğru 3x3, 5x5 ve 7x7 olarak seçilmiştir. Filtre sayısı ise konvolüsyon katmanlarının hepsinde 128 olarak seçilmiştir.

- Toplu Normalleştirme Katmanı: Aktivasyon fonksiyonundan önce kullanılarak ortalama ve varyansı normalize eder. Bu sayede tasarlanan ağın öğrenme performansı artar.

- ReLU Katmanı: Yapay sinir ağlarının doğrultucusu olarak tanımlanabilecek bu katman, $f(x)=\max (0, x)$ fonksiyonunu kullanarak verinin aktivasyonunu sağlamaktır.

- Havuzlama Katmanı: Giriş matrisinin belirlenen boyutlar içerisinde bulunan elamanlarından istenen özelliklere göre seçimini sağlar. Ortalama, maksimum havuzlama katmanı gibi çeşitleri vardır. Çalışmada bulunan G-ESA ve İ-ESA'da 3x3 boyutundaki maksimum havuzlama katmanı kullanılmıştır. Bu katman 3x3'lük maske içerisindeki maksimum değeri alarak çıkış katmanına ulaştırır.

- Bırakma Katmanı: Yapay sinir ağlarının problemlerinden biri olan aşırı uyum probleminin oluşmaması için kullanılmıştır. Katmanlar arası bazı bağlantıları pasifize ederek aşırı uyum sorununu engeller.

- Tam Bağlantılı Katman: Giriş ve çıkış katmanları arasında bütün veriler arasında bağ kurarak her giriş değerinin çıkış değeri arasındaki ilişkiyi belirler. 
- Softmax Katmanı: Sınıflandırma problemlerinde kullanılan bu katman, giriş verisini sınıf sayısı kadar olasılığa softmax fonksiyonunu kullanarak dönüştürür.

Algoritma 1'de gösterildiği gibi insanın ortamdaki konumuna göre robot farklı hızlar için set edilmiştir.

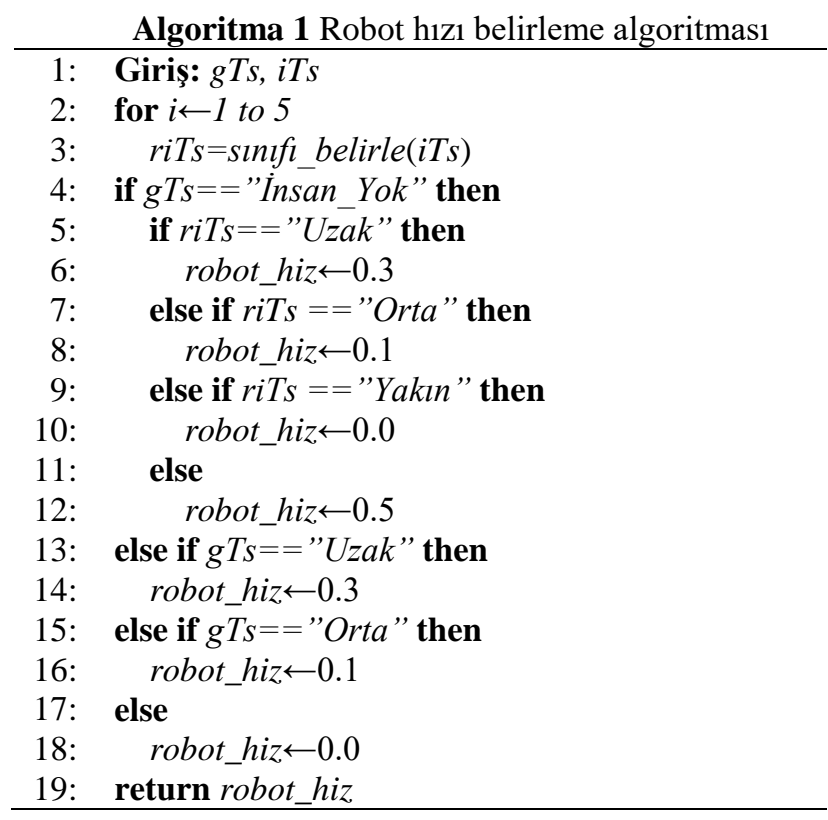

Algoritma 1'de $g T s$, iTs ve robot_hiz sırası ile görsel tehlike seviyesini, işitsel tehlike seviyesini ve robot programının çalışma hızını ifade etmektedir. İnsanlarda görme işitmeye nazaran bir cismin nerede olduğunu saptamak için daha fazla kullanılan fonksiyondur. Bu sebepten dolayı geliştirilen robot hızı belirleme algoritmasında görme yetisi daha öncelikli yeti olarak atanmıștır. Ayrıca işitilen sesin genliği ortamdan ve ses kaynağının farklılığından dolayı, ses kaynağının uzaklığını tam olarak ölçmek mümkün değildir. Bundan dolayı sınıfi_belirle() fonksiyonu kullanılarak artarda işitilen beş sesten hangi ses tehlike sınıfı daha fazla algılandığı belirlenir. Bu belirleme sayesinde robotun çalışma hızı tayin edilir.

\section{Robot-İnsan Etkileşimi İçin Çalışma Ortamı}

Geliştirilen yazılım, KUKA KR Agilus KR6 R900 sixx robotunun insanlar ile birlikte güvenli bir şekilde çalışabilmesini sağlamak için kullanılmıştır. Hazırlanan deney düzeneği Şekil 3’te sunulmuştur.

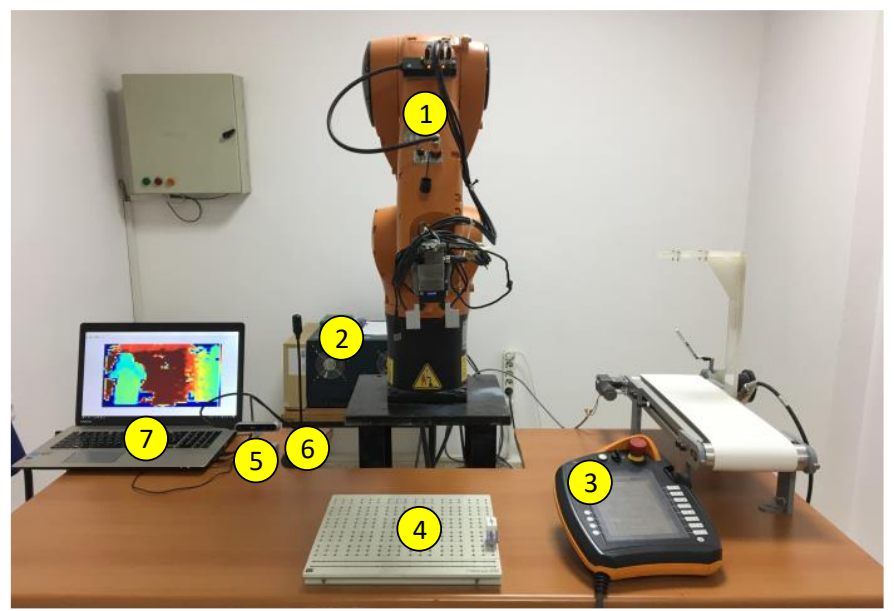

Şekil 3. Deney Düzeneği 
Bu çalışmada kullanılan endüstriyel robot sırası ile manipülatör (1), robot kontrol ünitesi (2) ve akıllı tablet (3) kısımlarından oluşmaktadır. Geliştirilen yazılımın test edileceği senaryo olan elektronik devre elemanı testi için diyot ve uygun test devresi (4) numarada gösterilmektedir. Derinlik kamerası (5) ve mikrofon (6) ile GİREY diş ortamdan görüntü ve ses verilerini elde etmektedir. Yazılımın çalışacağı PC (7) ile robot kontrol ünitesi arasında iletişim TCP-IP vasıtası ile KUKAVARPROXY yazılımı kullanılarak sağlanmıștır. Ayrıca kameranın görüş açısındaki 0-100 cm yakın, ikinci 100-170 cm orta ve ortadan sonrası uzak tehlike sınıfı olarak Şekil 4'te gösterildiği gibi belirlenmiştir.

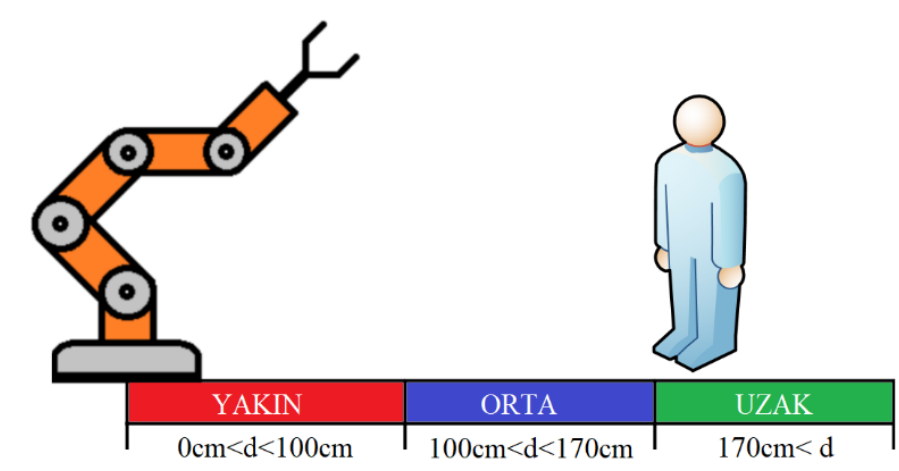

Şekil 4 . Tehlike seviyeleri

\section{Sonuçlar}

Robotun çalışma ortamında bulunan bir insanı fark edebilmesi için kullanılan G-ESA'nın eğitimi için İnsan Yok, Yakın, Orta ve Uzak olmak üzere dört farklı sınıf için toplam iki bin adet görüntü verisi toplanmıştır. Toplanan verilerin yüzde \%90'1 eğitim ve \%10'u test için kullanılmıştır. Önerilen G-ESA'nın eğitim işlemi sonrası test verileri kullanılarak farklı sınıflandırma algoritmaları için hata oranları Tablo 1'de sunulmuştur.

Tablo 1. Görüntü test verileri için hata oranları

\begin{tabular}{|c|c|}
\hline Kullanılan Algoritma & Hata Oranı (\%) \\
\hline G-ESA & 0.00 \\
\hline DVM & 0.50 \\
\hline En Yakın k Komşu & 1.50 \\
\hline Karar Ağacı & 5.00 \\
\hline
\end{tabular}

Tablo 1'den anlaşılabileceği üzere, önerilen G-ESA'nın test doğruluk oranı \%100'dür. Diğer bir kullanılan yapı olan İ-ESA'nın eğitimi için İnsan Yok, Yakın, Orta ve Uzak olmak üzere dört farklı sınıf için toplam bin adet 500ms'lik ses verisi toplanmıştır. Toplanan verilerin yüzde \%90'1 eğitim ve \%10’u test için kullanılmıştır. Önerilen İ-ESA'nın eğitim işlemi sonrası test verileri kullanılarak farklı sınıflandırma algoritmaları için hata oranları Tablo 2'de sunulmuştur.

Tablo 2. Ses test verileri için hata oranları

\begin{tabular}{|c|c|}
\hline Kullanılan Algoritma & Hata Oranı (\%) \\
\hline İ-ESA & 38.75 \\
\hline DVM & 43.75 \\
\hline Karar Ağacı & 45.00 \\
\hline En Yakın k Komşu & 53.75 \\
\hline
\end{tabular}

Hem G-ESA hem de İ-ESA literatürde sınıflandırma problemi için sıklıkla kullanılan en yakın k komşu, DVM ve karar ağacı algoritmaları karşılaştırılmıştır. Toplanan veriler belirlenen algoritmalar ile sınıflandırılmış ve en iyi sonuçlar önerilen G-ESA ve İ-ESA tarafından üretildiği görülmüştür. Konuşan insanın mesafesini algılamakta zorlanan İ-ESA, algıladığı sesin insan mı yoksa robotun çalışma sesi mi olduğunu anlamakta \% 88.1 'lik bir başarım 
oranına sahiptir. Bu başarım oranı robot kontrol kısmında bulunan sınıfi_belirle() fonksiyonu kullanılarak arttırılmıştır. GİREY yazılımını test etmek için oluşturulan senaryo ve robot hızı grafiği Şekil 5 ve Şekil 6'da sırası ile sunulmuştur.
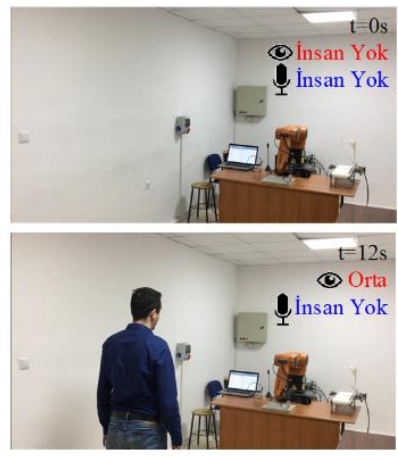
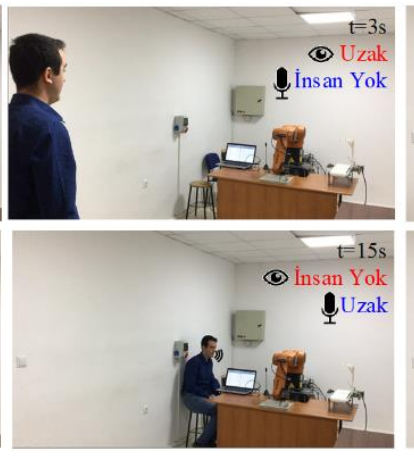
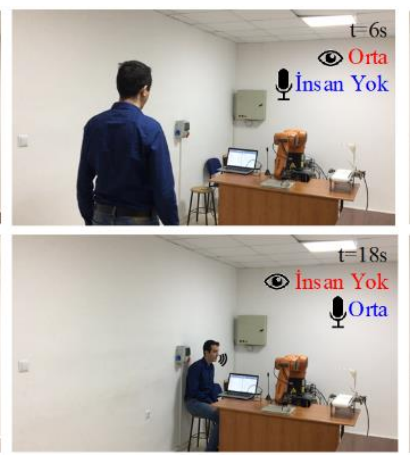

Şekil 5. Anlık olarak GIiREY testi

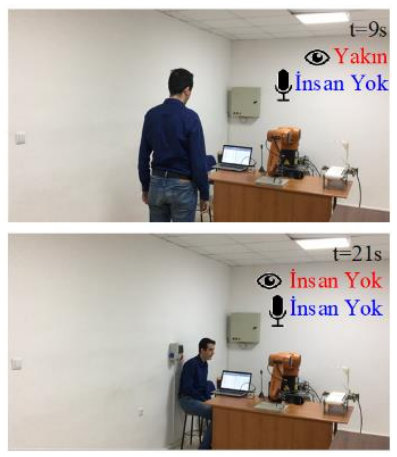

Şekil 5'te zamana bağlı olarak robotun çalışma ortamında olan bir insanın bulunduğu konuma göre belirlenen tehlike sınıfları verilmiștir. Bu tehlike sınıflarından kırmızı yazı ile belirtilen G-ESA'nın çıkışıyken, mavi ile renklendirilen İ-ESA'nın çıkışını sembolize etmektedir. Bu olay gerçekleşirken GİREY'in robota uyguladığı hız Şekil 6'da sunulmuştur.

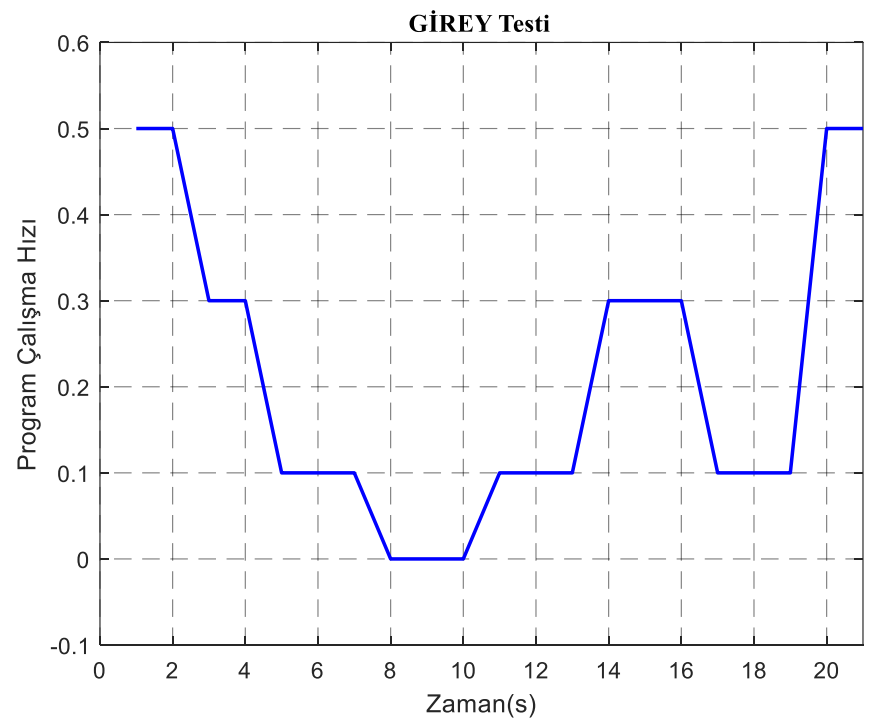

Şekil 6. GİREY testi sırasında robot programının çalışma hızı

Robotun otonom olarak çalışma hızı sıfir ile bir aralığında ölçeklenmiş olup, herhangi bir kazaya sebebiyet vermemek için bu deney sırasında robot hızı en fazla maksimum hızının $\% 50$ olan 0.5 'te çalıştırılmıştır. Tasarlanan robot kontrol kısmı istenilen işlemi mutlak doğrulukla gerçekleştirmiş olup, Şekil 6'de görüneceği üzere robotun hızını anlık olarak doğru bir şekilde ayarlamıştır.

\section{Değerlendirme}

Bu çalışma, son günlerde insanların robotlar ile birlikte aynı ortamı paylaşmaya başlamalarının artmasına paralel olarak önem kazan İRE konusu ile ilgili olarak insan güvenliği ele alınmıştır. Yapılan bu çalışmanın daha önce yapılmış çalışmalardan farkı; robota veya insana özel olarak tasarlanmış bir algılayıcı sistemin eklenmemesi ve robot ile çalışacak kişinin robotik alanda bilgi ve tecrübeye sahip olmasına gerek kalmadan geliştirilen GíREY 
yazılımı sayesinde insan güvenliğinin de sağlandığı bir sistem oluşturulmasıdır. GİREY görme, işitme ve robot kontrolü olmak üzere üç temel kısımdan meydana gelmiştir. Görme kısımda bir adet derinlik kamerası ve GESA'dan oluşturulmuştur. Derinlik kamerasından alınan görüntüler ile eğitilen G-ESA, görmeye bağlı olarak robotun çalıştığı ortamda insanını bulunup bulunmadığı, insan ile robot arasındaki mesafenin \%100 doğrulukla belirleyebilmektedir. İşitme kısmı ise bir adet mikrofon ve İ-ESA'dan oluşmaktadır. Mikrofon vasıtası ile alınan ses verileri ile eğitilen İ-ESA, G-ESA'nın aksine sadece ortamda insan var mı sorusuna cevap verebilecek niteliktedir. İ-ESA'nın test sonuçlarına bakıldığında G-ESA gibi ortamda bulunan insanın robota olan mesafesini verebilecek düzeyde yeterli değildir. Bunun nedeni, farklı tehlike düzeylerinde konuşan insanların laboratuvar şartlarında seslerinin yankı yaparak genlik düzeylerinin bir birine çok yakın olması ve robotun çalışma sesinin insan sesini bastırmasıdır. İnsanlarda görmeye bağlı olarak ortamda bulunan bir insanı sese nazaran daha net tahmin edebildiklerinden dolayı insandan esinlenerek oluşturulan GİREY yapısında bulunan G-ESA'nın İ-ESA'ya göre daha iyi sonuç vermesi anlamlıdır. Çok kanallı iletişim yöntemi kullanan GİREY yapısında bulunan son kısım, robot kontrol kısmıdır. Bu kısımda görme yetisinden alınan daha olumlu sonuçlardan dolayı elde edilen tehlike düzeylerinde öncelik G-ESA'dan gelen sonuçlara verilmiştir. Ancak robotun çalıştığı ortamın bir kısmı kameranın görüş açısında bulunduğu için kalan kısımlarda ise İ-ESA'dan gelen sonuçlar geliştirilen sinıfi_belirle() fonksiyonundan geçirildikten sonra kullanılmıştır. Elde edilen veriler göz önünde bulundurulduğunda, robotla birlikte çalışan insan GİREY sayesinde daha güvenli olarak çalışabileceği sonucuna varılmıştır.

Gelecek çalışmalarda, bu çalışmada elde edilen iki hisse ek olarak insan güvenliğinin artırılması için robota dokunma hissinin de eklenmesi düşünülmektedir.

\section{Bilgi Notu}

Yapılan bu çalışma, "İnsan-Robot Etkileşimini Kullanarak Yapay Zekâ Temelli Kendini Programlayabilir Robot Yazılımının Geliştirilmesi" isimli doktora tezi çalışması kapsamına yapılmıştır.

\section{Kaynaklar}

[1] J. Fong, H. Rouhani, and M. Tavakoli, A Therapist-Taught Robotic System for Assistance During Gait Therapy Targeting Foot Drop, IEEE Robot. Autom. Lett., 2019; 4(2): 407-413.

[2] J.-F. Lafleche, S. Saunderson, and G. Nejat, Robot Cooperative Behavior Learning Using Single-Shot Learning From Demonstration and Parallel Hidden Markov Models, IEEE Robot. Autom. Lett., 2018; 4(2): 193-200.

[3] A. Yatsuda, T. Haramaki, and H. Nishino, A robot motion design scheme for watching the elderly based on human gesture sensing, Internet of Things, 2019; 5 168-179.

[4] G. Du, M. Chen, C. Liu, B. Zhang, and P. Zhang, Online Robot Teaching with Natural Human-robot Interaction, IEEE Trans. Ind. Electron., 2018; 0046.

[5] J. Zurada, A. L. Wright, and J. H. Graham, A neuro-fuzzy approach for robot system safety, IEEE Trans. Syst. Man Cybern. Part C Appl. Rev., 2001; 31(1): 49-64.

[6] F. Xia, F. Campi, and B. Bahreyni, Tri-Mode Capacitive Proximity Detection Towards Improved Safety in Industrial Robotics, IEEE Sens. J., 2018; 18(12): 5058-5066.

[7] S. Lee, S. Hara, and Y. Yamada, A safety measure for control mode switching of Skill-Assist for effective automotive manufacturing, IEEE Trans. Autom. Sci. Eng., 2010; 7(4): 817-825.

[8] N. Najmaei and M. R. Kermani, Applications of artificial intelligence in safe human-robot interactions, IEEE Trans. Syst. Man, Cybern. Part B Cybern., 2011; 41(2): 448-459.

[9] E. A. Sisbot and R. Alami, A human-aware manipulation planner, IEEE Trans. Robot., 2012; 28(5): 1045-1057.

[10] G. B. Avanzini, N. M. Ceriani, A. M. Zanchettin, P. Rocco, and L. Bascetta, Safety control of industrial robots based on a distributed distance sensor, IEEE Trans. Control Syst. Technol., 2014; 22(6): 2127-2140.

[11] C. Miyata, K. Chisholm, J. Baba, and M. Ahmadi, A Limb Compliant Sensing Strategy for Robot Collision Reaction, IEEE/ASME Trans. Mechatronics, 2016; 21(2): 674-682.

[12] S. Savazzi, V. Rampa, F. Vicentini, and M. Giussani, Device-Free Human Sensing and Localization in Collaborative Human-Robot Workspaces: A Case Study, IEEE Sens. J., 2016; 16(5): 1253-1264.

[13] M. Kimmel and S. Hirche, Invariance control for safe human-robot interaction in dynamic environments, IEEE Trans. Robot., 2017; 33(6): 1327-1342.

[14] E. Dean-Leon, K. Ramirez-Amaro, F. Bergner, I. Dianov, and G. Cheng, Integration of Robotic Technologies for Rapidly Deployable Robots, IEEE Trans. Ind. Informatics, 2018; 14(4): 1691-1700.

[15] M. C. Bingol and O. Aydogmus, Implementation of speech recognition for robot control using support vector machine, in International Eurasian Conference on Science, Engineering and Technology (EurasianSciEnTech), 2018; 814-819. 